\title{
FAKTOR YANG MEMPENGARUHI KEJADIAN STUNTING PADA BALITA 24-60 BULAN DI WILAYAH KERJA PUSKESMAS LAKUDO KABUPATEN BUTON TENGAH
}

\author{
Indra dewi ${ }^{1}$, Suhartatik ${ }^{2}$, Suriani $^{3}$ \\ ${ }^{1}$ STIKES Nani Hasanuddin Makassar \\ ${ }^{2}$ STIKES Nani Hasanuddin Makassar \\ ${ }^{3}$ STIKES Nani Hasanuddin Makassar
}

Alamat Korespondensi : (indradewi@stikesnh.ac.id/082394509509)

\begin{abstract}
ABSTRAK
Stunting adalah kondisi gagal tumbuh pada bayi ( 0 - 11 bulan) dan anak balita ( $12-59$ bulan) akibat dari kekurangan gizi kronis terutama dalam 1000 hari pertama kehidupan sehingga anak terlalu pendek untuk usianya. Tujuan dalam penelitian ini adalah untuk mengetahui faktor yang mempengaruhi kejadian stuntingdi wilayah kerja Puskesmas Lakudo Kabupaten Buton Tengah. Desain penelitian yang digunakan metode penelitian analitik dengan pendekatan cross sectional. Jumlah sampel yang didapatkan sebanyak 80 responden.Instrument dalam penelitian berupa pengukuran tinggi badan menggunakan microtoise dan kuesioner. Data yang telah terkumpul diolah dan dianalisis dengan menggunakan uji Chi-square melalui program SPSS dengan batas kemaknaan $(\alpha=0,05)$. Hasil analisis bivariate didapatkan pola makan $(\rho=0,001)$, kebersihan/hygiene $(\rho=0,242)$, dan pemanfaatan pelayanan kesehatan $(\rho=0,027)$.dikarenakan nilai $\rho<\alpha=0,005$ sehingga dapat disimpulkan bahwa ada hubungan antara pola makan dan pemanfaatan pelayanan kesehatan dengan kejadian stunting pada balita 24-60 bulan di wilayah kerja Puskesmas Lakudo kabupaten Buton Tengah. Sedangkan kebersihan/hygiene tidak memiliki hubungan dengan kejadian stuntingpada balita 24-60 bulan di wilayah kerja Puskesmas Lakudo kabupaten Buton Tengah di karenakan nilan $\rho>\alpha=0,05$. Kesimpulan dalam penelitian ini adalah adanya hubungan antara pola makan dan pemanfaatan pelayanan kesehatan terhadap kejadian stunting dan juga tidak ada hubungan antara kebersihan/hygiene dan kejadian stunting.
\end{abstract}

Kata Kunci : Kebersihan, Pola makan, Pemanfaatan pelayanan kesehatan, Stunting.

\section{PENDAHULUAN}

Salah satu tantangan utama yang saat ini dihadapi sektor kesehatan di Indonesia adalah masalah gizi balita. Balita adalah penerus masa depan kita, balita juga menentukan masa depan bangsa, balita sehat akan menjadikan balita yang cerdas. Balita salah satu golongan umur yang rawan penyakit apabila terjadi kekurangan pangan dan gizi.Defisiensi zat gizi pada balita dapat menyebabkan balita kurang gizi, infeksi penyakit dan mempengaruhi kecerdasan anak. Dampak dari kurang gizi adalah akan terganggunya pertumbuhan dan perkembangan pada balita (supariasa, dkk 2017).

Stunting menggambarkan status gizi kurang yang bersifat kronik pada masa pertumbuhan dan perkembangan sejak awal kehidupan. Keadaan ini dipresentasikan dengan nilai $z$-score tinggi badan menurut umur (TB/U) kurang dari -2 standar deviasi (SD) berdasarkan standar pertumbuhan menurut WHO (Supariasa, 2017). Indonesia adalah salah satu dari tiga negara dengan prevalensi stuntingtertinggi di Asia
Tenggara.Penurunan angka kejadian stuntingdi Indonesia tidak begitu signifikan dibandingkan dengan Myanmar, Kamboja dan Vietnam. Bahkan pada 2013 prevalensi stuntingdi Indonesia justru mengalami peningkatan lebih dari 9 juta anak di Indonesia mengalami stunting(Fikawati, 2017).

Berdasarkan data Riskesdas tahun 2018, prevalensi stuntingpada tahun 2013 sebesar $37,2 \%$ dan mengalami penurunan sebesar $6,4 \%$ pada tahun 2018 menjadi $30,8 \%$. Masalah kesehatan masyarakat dianggap berat bila prevalensi pendek sebesar 30-39 persen dan serius bila prevalensi pendek $\geq 40$ persen.(Trihono, dkk 2015).

Data dari dinas kesehatan provinsi Sulawesi Tenggara menyebutkan dari 100 Balita terdapat 12 balita kurus, 30 balita stunting dan 5 balita mengalami kegemukan (obesitas). Kondisi stunting di Sulawesi Tenggara tahun 2018 juga mengalami peningkatan jika di bandingkan tahun 2016 dan tahun 2017, yakni dari $29,6 \%$ menjadi $36,4 \%$ atau meningkat $6,8 \%$ dengan prevalensi tertinggi terdapat di kabupaten Buton Tengah (Menkes RI, 2018 di kutip 
dalam RRI). Prevalensi stuntingdi wilayah butonpada tahun 2013 yaitu 49,61\% (Bappenas, 2017). Data kejadian stunting di wilayah kerja puskesmas Lakudo belum diketahui secara pasti angka kejadiannya dan Jumlah anak stunting yang terdata kurang lebih 12 orang.

Berdasarkan uraian di atas peneliti ingin mengetahui "Faktor yang mempengaruhi stunting pada balita umur 24 - 60 bulan di wilayah kerja puskesmas Lakudo kabupaten Buton Tengah

\section{BAHAN DAN METODE}

Lokasi, Populasi Dan Sampel

Penelitian ini akan dilakukan di Wilayah kerja Puskesmas Lakudo Kabupaten Buton Tengah. Waktu penelitiannya yaitu pada tanggal 21 Desember 2018 sampai 04 Januari 2019.Penelitian ini dilakukan dengan menggunakan metode penelitian analitik dengan pendekatan cross-sectional.

Populasi dalam penelitian ini adalah semua balita usia 24-60 bulan di wilayah kerja Puskesmas Lakudo Kabupaten Buton Tengah sebanyak 411 orang.Sampel dalam penelitian ini adalah balita yang berusia 24-60 bulan sebanyak 80 orang.

1. Kriteria inklusi

a. Balita yang berusia 24-60 bulan

b. Ibu balita yang bersedia menjadi responden

c. Ibu dan balita yang berada di tempat pada waktu dilakukan penelitian

2. Kriteria eksklusi

a. Balita yang cacat atau sakit

b. Ibu balita yang tidak dapat membaca.

\section{Pengumpulan Data}

1. Data primer

Data yang digunakan peneliti dari hasil penyebaran kuesioner, pengukuran langsung tinggi badan anak menggunakan microtoise dengan ketelitian $0,1 \mathrm{~cm}$ di wilayah kerja Puskesmas Lakudo Kabupaten Buton Tengah.

2. Data sekunder

Data sekunder dalam penelitian ini adalah data yang diperoleh dari wawancara dengan petugas kesehatan Puskesmas Lakudo dan juga dari data Puskesmas Lakudo Kabupaten Buton Tengah.

\section{Analisis Data}

1. Analisis Univariat

Analisis univariat dilakukan pada tiap variabel dari hasil penelitian untuk melihat distribusi frekuensi dengan melihat persentase masing-masing variabel penelitian.Analisis univariat ini digunakan untuk mengetahui proporsi dari masingmasing variabel penelitian.

2. Analisis Bivariat

Analisis bivariat berfungsi untuk mengetahui hubungan antar variabel independen dan variabel dependen

\section{HASIL}

1. Analisis Univariat

Tabel 1. Distribusi Karakteristik Responden di wilayah kerja Puskesmas Lakudo Kabupaten Buton Tengah $2018(n=80)$

\begin{tabular}{|l|c|c|}
\hline Karakteristik & $\mathrm{n}$ & $\%$ \\
\hline Usia Responden & & \\
$18-25$ & 6 & 7,5 \\
$26-33$ & 42 & 52,5 \\
\hline Usia balita & & \\
$21-30$ & 12 & 15, \\
$51-60$ & 27 & 33,8 \\
\hline $\begin{array}{l}\text { Jenis Kelamin } \\
\text { Perempuan } \\
\text { Laki-laki }\end{array}$ & 41 & 51,2 \\
\hline $\begin{array}{l}\text { Pendidikan } \\
\text { SMA }\end{array}$ & 39 & 48,8 \\
Diploma & 39 & 48,8 \\
\hline $\begin{array}{l}\text { Pekerjaan } \\
\text { IRT }\end{array}$ & 5 & 6,3 \\
PNS & 58 & 72,5 \\
\hline Jumlah Anggota & 10 & 12,5 \\
Keluarga & & \\
3-5 orang & 62 & 77,5 \\
>5 orang & 18 & 22,5 \\
\hline Riwayat Pemberian \\
ASI & & \\
<2 tahun & 42 & 52,5 \\
2 tahun & 38 & 47,5 \\
\hline Kejadian stunting \\
Ya & & \\
Tidak & 55 & 68,8 \\
\hline
\end{tabular}

Berdasarkan tabel 1 di atas dapat dijelaskan bahwa jumlah seluruh responden sebanyak 80 . Usia responden terbanyak yaitu 26-33 tahun sebanyak 42 $(52,5 \%)$ sedangkan usia responden paling sedikit $18-25$ sebanyak 6 (7,5\%). Usia balita terbanyak yaitu $51-60$ bulan sebanyak 27 balita $(33,8 \%)$ dan paling sedikit usia 21-30 sebanyak 12 balita $(15 \%)$. Jenis kelamin balita terbanyak yaitu perempuan sebanyak 41 balita $(51,2 \%)$ dan laki-laki sebanyak 39 balita $(48,8 \%)$. Pendidikan Responden terbanyak yaitu SMA sebanyak 39 responden $(48,8 \%)$ dan paling sedikit berpendidikan Diploma sebanyak 5 responden (6,3\%).Pekerjaan responden terbanyak yaitu IRT sebanyak 58 responden $(72,5 \%)$ dan paling sedikit PNS sebanyak 10 (12,5\%).Jumlah anggota 
keluarga terbanyak yaitu 3-5 orang sebanyak 62 orang $(77,5)$ dan 18 responden dengan Jumlah anggota keluarga $>5$ orang. Riwayat pemberian ASI terbanyak yaitu $<2$ tahun sebanyak 42 $(52,5 \%)$ dan 2 tahun sebanyak 38 (47,5\%). Balita yang mengalamistuntingsebanyak 55 balita $(68,8 \%)$ sedangkan balita yang tidak mengalami stunting sebanyak 25 balita $(31,2 \%)$

\section{Analisis Bivariat}

Tabel 2. Hubungan antara Pola Makan, kebersihan/hygiene dan Pemanfaatan Pelayanan kesehatan dengan kejadian stunting $(\mathrm{n}=80)$.

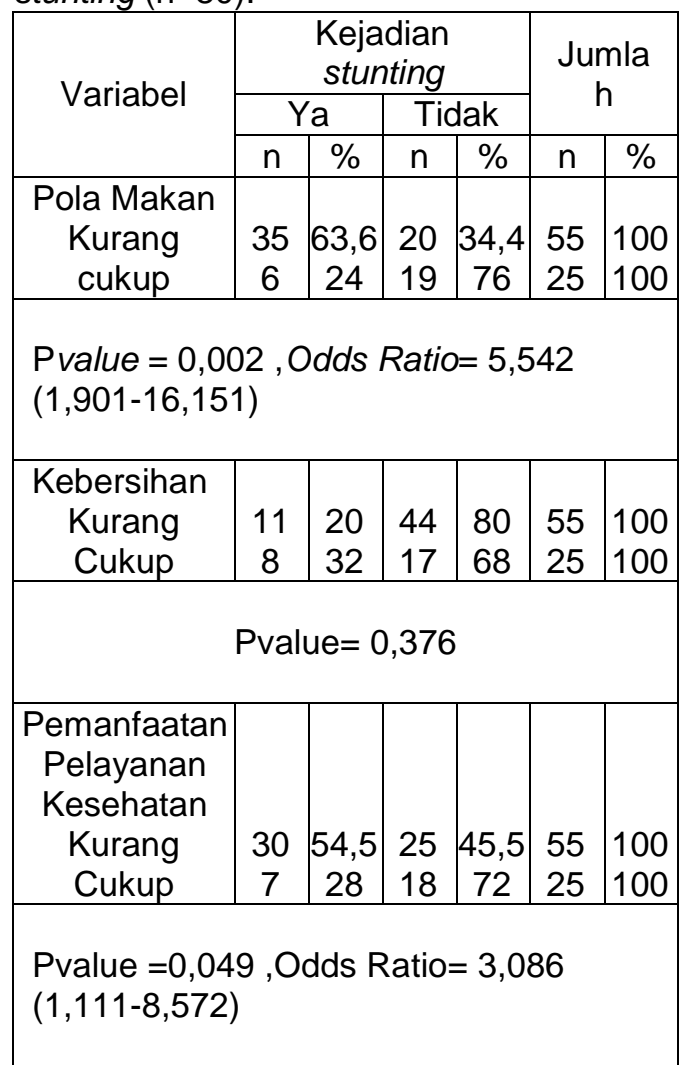

Berdasarkan Tabel 2 menunjukkan bahwa Hasil uji statistik chi square menunjukkanPvalue $=0,002$ atau $(p<$ $0,05)$ yang berarti ada hubungan antara pola makan dengan kejadian stunting pada balita. Dari uji statistika ini juga diperolehnilai OR (odds Ratio) $=5,542$ dengan $95 \% \mathrm{Cl}=(1,901-16,151)$ yang berarti balitayang memiliki pola makan kurang berpeluang 5,542kali lebih tinggi mengalami stuntingdibandingkan dengan balita yang memiliki pola makan cukup.

Berdasarkan Tabel 2. Hasil uji statistik chi square menunjukkan Pvalue $=$ 0,376 atau $(p>0,05)$ yang berarti tidak ada hubungan antara kebersihan dengan kejadian stunting pada balita.
Berdasarkan Tabel 2 menunjukkan bahwa hasil uji statistik chi square menunjukkanPvalue $=0,049$ atau $(p<$ $0,05)$ yang berarti ada hubungan antara pemanfaatan pelayanan kesehatan dengan kejadian stunting pada balita. Dari uji statistika ini juga diperolehnilai OR (odds Ratio $)=3,086$ dengan $95 \% \mathrm{Cl}=(1,111$ 8,572)yang berarti balita yang kurang memanfaatkan pelayanan kesehatan berpeluang 3,086 kali lebih tinggi mengalami stuntingdibandingkan dengan balita yang cukup memanfaatkan pelayanan kesehatan.

\section{PEMBAHASAN}

1. Hubungan antara pola makan dengan kejadian stunting pada balita

Berdasarkan penelitian yang telah dilakukan di wilayah kerja Puskesmas Lakudo didapatkan 35 balita yang memilikipola makan kurang dan mengalami stunting. Hal ini dimungkinkan dipengaruhi oleh pengetahuan ibu mengenai jadwal makan dan frekuensi makan balita kurang teratur serta memiliki penyakit infeksi misalnya diare atau ISPA.ibu yang memiliki pengetahuan yang kurang baik terhadap gizi maka akan berdampak buruk pula pada status gizi anak.

Dalam penelitian ini terdapat pula 20 balita yang memiliki pola makan kurang dan tidak mengalami stunting.hal ini di duga frekuensi makan balita sedikit tapi sering dengan kandungan gizi yang cukup serta tidak mengalami penyakit infeksi serta memanfaatkan pelayanan kesehatan.

Sebaliknya yang memiliki pola makan cukup sebanyak 6 balita tetapi mengalami stunting. Hal ini di duga disebabkan karena pola makan yang cukup bukan satu-satunya faktor yang menjadikan balita terhindar dari kejadian stunting tetapi ada beberapa faktor lain seperti salah satunya adalah penyakit infeksi seperti ISPA atau diare sehingga penyerapan energi dalam makanan akan berkurang. Dan balita yang memiliki pola makan cukup dan tidak mengalami stunting sebanyak 19 balita dikarenakan pola makan anak dan kandungan gizi yang diberikan cukup untuk memenuhi kebutuhan pertumbuhan balita.

Hasil uji statistik chi square diperoleh nilai Pvalue $=0,002$ atau $(\mathrm{p}<0,05)$ sehingga $\mathrm{Ha}$ diterima yang berarti ada hubungan antara pola makan dengan kejadian stunting pada balita.

Dalam penelitian Nadimin (2017), menunjukkan Pola makan dalam keluarga 
berpengaruh terhadap pemenuhan asupan zat gizi anggota keluarga terutama anak balita. Melalui pola makan keluarga yang baik makan akan lebih mudah memenuhi kebutuhan gizi anggota keluarga sebaliknya pola makan yang kurang baik akan beresiko pada penurunan asupan zat gizi anak sehingga anak lebih beresiko mengalami gangguan pertumbuhan atau stunting.

Penelitian ini sejalan dengan penelitian sebelumnya oleh Rahmayana, dkk (2014), yang menunjukkan hasil analisis pola makan dengan kejadian stunting anak usia 24-59 bulan di posyandu Asoka II wilayah pesisir kelurahan Barombong kecamatan Tamalate Kota Makassar tahun 2014 didapatkan hasil ujistatistic chi-square $\rho=0,007 \quad<(\alpha=0,05)$ maka hipotesis $\mathrm{Ha}$ diterima yang berarti ada hubungan yang signifikan antara perhatian/dukungan ibu terhadap anak dalam praktik pola makan dengan kejadian stunting. dimana digambarkan pada hasil penelitian ini yang termasuk dalam kategori pola makan baik menunjukkan $55,6 \%$ tinggi badan anak normal.

Pola makan yang seimbang yaitu sesuai dengan kebutuhan disertai pemilihan makanan yang tepat akan melahirkan status gizi yang baik. Asupan makanan yang melebihi kebutuhan tubuh akan menyebabkan kelebihan berat badan dan penyakit lain yang disebabkan oleh kelebihan zat gizi. Sebaliknya, asupan makanan kurang dari yang dibutuhkan akan menyebabkan tubuh menjadi kurus dan rentan terhadap penyakit. Kedua tersebut sama tidak baiknya, sehingga disebut gizi salah Keadaan gizi salah akibat kurang makan dan berat badan yang kurang merupakan hal yang banyak terjadi di berbagai daerah atau Negara miskin (Sulistyoningsih, 2012).

Berdasarkan penelitian di atas penulis dapat menyimpulkan bahwa pola makan pada anak merupakan landasan yang penting dalam proses pertumbuhan yang memerlukan dukungan dan perhatian orang tua dalam hal pemenuhan gizi pada balita.

2. Hubungan kebersihan dengan kejadian stunting pada balita

Berdasarkan penelitian yang telah dilakukan di wilayah kerja Puskesmas Lakudo didapatkan 44 balita yang memiliki kebersihan kurang dan tidak mengalami stuntingdiduga karena kebersihan yang kurang bukanlah satu-satunya faktor yang menjadikan balita mengalami stunting dan juga kurangnya motivasi ibu dalam pemenuhan gizi pada balita .Balita yang kebersihanya kurang dan mengalami stunting sebanyak 11 balita dimungkinkan karena makanan yang dikonsumsi dengan kebersihan yang kurang baik menyebabkan infeksi yang biasanya disertai dengan pengurangan nafsu makan dan muntah-muntah. Kondisi ini dapat menurunkan keadaan gizi balita dan berimplikasi buruk terhadap kemajuan pertumbuhan anak. Hasil uji statistik chi square menunjukkan $P$ value $=0,376$ atau $(p>0,05)$, sehingga Ha ditolak yang berarti tidak ada hubunganantara kebersihan dengan kejadian stunting pada balita.

Tidak sejalan dengan penelitian Octaviana (2016), menunjukkan hasil uji statistic didapatkan nilai $\rho=0,017 \quad(<0.05)$, sehingga terdapat hubungan antara kejadian stunting dengan kebersihan/hygiene.

Menjaga kebersihan memang harus dimulai dari balita hingga dari lingkungan balita bahkan kebersihan peralatan yang digunakan, kebersihan bahan-bahan makanan, cara kebersihan, dan juga cara memasaknya. Jangan sampai bahan makanan yang dikonsumsi sang balita di kerumunin serangga. Akibat dari kebersihan yang kurang, maka anak akan sering sakit, misalnya diare, kecacingan, dan sebagainya. Diare dapat menyebabkan kurang gizi dan dapat memperburuk keadaan, karena selama diare akan mengalami kehilangan zat gizi dari tubuh (Hapsari, 2014).

Penulis berasumsi bahwa menjaga kebersihan balita harus tetap diperhatikan walau bukan menjadi satu-satunya faktor pencetus untuk terjadi stunting namun dapat beresiko pada balita mengalami stunting.

3. Hubungan pemanfaatan pelayanan kesehatan dengan kejadian stunting pada balita

Berdasarkan penelitian yang telah dilakukan di wilayah kerja Puskesmas Lakudo menunjukkan bahwa balita yang kurang memanfaatkan pelayanan kesehatan memiliki proporsi tertinggi mengalami kejadian stuntingdengan jumlah 30 balita.Sementara balita yang cukup memanfaatkan sarana kesehatan memiliki proporsi tertinggi tidak mengalami kejadian stuntingdengan jumlah 18 balita. Hasil uji statistik chi square menunjukkan Pvalue = 0,049 atau $(p<0,05)$, sehingga Ha diterima yang berarti ada hubungan antara pemanfaatan sarana kesehatan dengan 
kejadian stunting pada balita.

Pelayanan kesehatan adalah akses atau keterjangkauan anak dan keluarga terhadap upaya pencegahan penyakit dan pemeliharaan kesehatan seperti imunisasi, pemeriksaan kehamilan, pertolongan persalinan, penimbangan anak, penyuluhan kesehatan dan gizi, serta sarana kesehatan yang baik seperti posyandu, puskesmas, praktek bidan atau dokter dan rumah sakit. Tidak terjangkaunya pelayanan kesehatan (karena jauh dan atau tidak mampu membayar), kurangnya pendidikan dan pengetahuan merupakan kendala masyarakat dan keluarga memanfaatkan secara baik pelayanan kesehatan yang tersedia.Hal ini dapat berdampak juga pada status gizi anak.

Sejalan dengan penelitian sebelumnnya oleh Rahmayana (2014), menunjukkan bahwa hasil analisis dengan uji statistic Chi-Square di dapat nilai $\rho=0,016<(\alpha=0,05)$ Maka hipotesis $\mathrm{Ha}$ diterima yang berarti ada hubungan yang signifikan antara pemanfaatan pelayanan kesehatan dengan kejadian stuntingpada balita.

Berbeda dengan penelitian Aramico,dkk (2013), Hasil uji statistik chisquare menunjukkan tidak ada hubungan yang signifikan antara akses dan pemanfaatan pelayanan kesehatan dengan status gizi $(p>0,05)$.

Penulis beransumsi adanya hubungan pemanfaatan pelayanan kesehatan dengan kejadian stunting dan terutama saat anak sakit, karena ketika anak sakit daya tahan tubuh anak atau imun tubuh melemah dan akan lebih mudah terserang penyakit apalagi jika anak tidak atau jarang dibawah ke posyandu untuk mendapatkan imunisasi. Karena ketika sakit nafsu makan akan berkurang dan akan diikuti pula dengan daya tahan tubuh semakin melemah, mudah terinfeksi penyakit lain dan pertumbuhan anak akan terganggu.

\section{KESIMPULAN}

1. Ada Hubungan Antara Pola Makan dengan Kejadian Stunting Pada Balita Usia 24-60 Bulan di Wilayah Kerja Puskesmas Lakudo

2. Tidak ada Hubungan Kebersihan/Hygiene dengan Kejadian Stunting Pada Balita Usia 24-60 Bulan di Wilayah Kerja Puskesmas Lakudo

3. Ada Hubungan Antara Pemanfaatan Pelayanan Kesehatan dengan Kejadian Stunting Pada Balita Usia 24-60 Bulan di Wilayah Kerja Puskesmas Lakudo

\section{SARAN}

1. Bagi masyarakat

Saran bagi masyarakat, khususnya bagi para ibu yang memiliki balita agar dapat memanfaatkan sumber daya manusia yang ada untuk bekerja sampingan dan memanfaatkan keterampilan atau keahlian khusus untuk digunakan dalam menambah penghasilan.Selain itu, pemanfaatan pekarangan rumah untuk memproduksi bahan makanan juga dapat digunakan untuk meningkatkan kesehatan keluarga.

2. Bagi Akademik

Menambah jumlah jam mata kuliah Keperawatan Komunitas guna memberikan cukup banyak ilmu sehingga menambah wawasan mahasiswa dalam penyusunan skripsi.

3. Bagi Mahasiswa

Disarankan mahasiswa yang berminat meneliti judul yang sama, agar variabel yang diteliti bisa diperdalam dan diteliti dalam variabel yang lebih besar.

\section{DAFTAR PUSTAKA}

Aramico, B.,Sudargo, T., \& Susilo, J. (2013). Hubungan Sosial Ekonomi, Pola Asuh, Pola Makan Dengan Stunting Pada Siswa Sekolah Dasar di Kecamatan Lut Tawar, Kabupaten Aceh Tengah, 1(3), 121-130.

Desyanti,C., \& Nindya, T.S. (2017). Hubungan Riwayat Penyakit Diare dan Praktik Higiene dengan Kejadian Stunting pada Balita Usia 24-59 Bulan di Wilayah Kerja Puskesmas Simolawang , Surabaya The Relations Between Diarrheal Disease History and Hygiene Practices with Stunting Incidences Among, 243-251. https://doi.org/10.20473/amnt.v1.i3.2017.243-251

Fikawati, S., Syafiq, A., Veratamala, A. 2017. Gizi Anak Dan Remaja.Depok : PT RajaGrafindo Persada

Hapsari, D. 2014. Waspadai Gizi Buruk Pada Balita. Jakarta Selatan: Tugu Publisher

Ibrahim, I. A., \& Damayati, D. S. (2014). Hubungan Pola Asuh Ibu Dengan Kejadian Stunting Anak Usia 24-59 Bulan Di Posyandu Asoka II Wilayah Pesisir Kelurahan Ba- rombong Kecamatan Tamalate Kota Makassar Tahun 2014, VI(2), 424-436 
Ramayulis, R., Kresnawan, T.,Iwaningsih, S.,Rochani, N.S. 2018.Stop Stunting dengan Konseling gizi.Jakarta : Penebar Swadaya Grup

Supariasa. I.D.N., Bakri, B., Fajar, I. 2017. Penilaian Status Gizi.Jakarta: Buku Kedokteran EGC 